\title{
Local Dopaminergic Modulation of the Motor Activity Induced by N-methyl-D-aspartate Receptor Stimulation in the Ventral Hippocampus
}

\author{
Lydia Giménez-Llort, Ph.D., Fu-Hua Wang, Ph.D., M.D., Sven Ove Ögren, Ph.D., \\ and Sergi Ferré, Ph.D., M.D.
}

Dopaminergic neurotransmission has been implicated in the motor activating effects induced by the local infusion of NMDA in the ventral hippocampus $(\mathrm{VH})$. The nucleus accumbens and the ventral tegmental area (VTA) have been proposed to be the main loci where dopamine is acting as a positive modulator of the $\mathrm{VH}$ NMDA receptor-mediated motor activating effects. However, the existence of a relatively high dopamine innervation and dopamine receptor density in the $\mathrm{VH}$ suggests the possibility of local dopamine/NMDA receptor interactions. This hypothesis was tested by studying the effects of the bilateral local $\mathrm{VH}$ infusion of NMDA (0.05, 0.1, 0.5 and $1.0 \mu \mathrm{g} /$ side), the dopamine D1/D5 receptor antagonist SCH 23390 (1 $\mu \mathrm{g} /$ side $)$ and the dopamine D2 receptor antagonist raclopride (1 and $5 \mu \mathrm{g} /$ side). Neither SCH 23390 nor raclopride induced any significant change in motor activity compared with the vehicle control group, but both compounds significantly antagonized the motor activation induced by NMDA. SCH 23390 (1 $\mu \mathrm{g} /$ side) was more potent that raclopride (minimal effective dose: $5 \mu \mathrm{g} /$ side). These results demonstrate the existence of a strong tonic facilitating effect of dopamine, acting preferentially at dopamine D1/D5 receptors, on NMDA receptor-mediated effects in the $\mathrm{VH}$.

[Neuropsychopharmacology 26:737-743, 2002]

(C) 2002 American College of Neuropsychopharmacology. Published by Elsevier Science Inc.
KEY WORDS: Glutamate; Dopamine D1 receptor; Dopamine D2 receptor; General motor activity; Locomotor activity; Rearing

From the Department of Neuroscience, Karolinska Institute, 17177 Stockholm, Sweden (LG-L, F-HW, SOO, SF), Department of Psychiatry and Forensic Medicine, School of Medicine, Autonomous University of Barcelona, 08193 Barcelona, Spain (LG-L), and National Institute on Drug Abuse, Intramural Research Program, National Institutes of Health, Baltimore, MD 21224, USA (SF).

Address correspondence to: Sergi Ferré, Behavioral Neuroscience Branch, National Institutes of Health, National Institute on Drug Abuse, Intramural Research Program, 5500 Nathan Shock Drive, P.O. Box 5180, Baltimore, MD 21224, Tel.: (410) 550 1586, fax: (410) 550 1648, E-mail: sferre@intra.nida.nih.gov

Received May 4, 2001; revised September 10, 2001; accepted November 9, 2001.

Online publication: $11 / 13 / 01$ at www.acnp.org/citations/ Npp111301206.
N-methyl-D-aspartate (NMDA) receptors are involved in the control of locomotor activity. Thus, systemic administration of NMDA in rodents induces pronounced motor effects, with an initial motor depression followed by motor activation (Giménez-Llort et al. 1995, 1997). The motor depressant effects seem to originate mainly in the striatum, where the local infusion of NMDA is associated with experimental parkinsonism (Klockgether and Turski 1993). Furthermore, the NMDA-induced motor depression has been shown to be adenosine dependent, since it is counteracted by low doses of adenosine antagonists and it inversely correlates with the striatal extracellular levels of adenosine (Giménez-Llort et al. 1995; Melani et al. 1999). On the other hand, the motor stimulant effects of NMDA probably originate in 
limbic areas. Thus, systemic administration of NMDA leads to an increase in the expression of the immediate early gene $c$-fos in the hippocampus and amygdala (Ferré et al. 1996; Radulovic et al. 2000). Moreover, local infusion of NMDA in the ventral hippocampus (VH) has been found to elicit motor activation in rodents (Yang and Mogenson 1987; Wu and Brudzynski 1995; Brudzynski and Gibson 1997; Bardgett and Henry 1999; Legault and Wise 1999).

Dopamine neurotransmission is involved in the motor activating effects of NMDA, since the systemic administration of dopamine antagonists counteracts the motor activation induced by the systemic or local $\mathrm{VH}$ administration of NMDA (Giménez-Llort et al. 1997; Bardgett and Henry 1999). Furthermore, the motor activation induced by NMDA infusion in the $\mathrm{VH}$ is abolished by 6-OHDA-induced lesions of the ventral tegmental area (VTA) (Wu and Brudzynski 1995). Two different mechanisms have been proposed to explain this interaction between hippocampal glutamate with dopamine. The accumbal hypothesis suggests that glutamate released from direct projections from the $\mathrm{VH}$ evokes impulse-independent dopamine release by acting at dopaminergic terminals in the nucleus accumbens (Wu and Brudzynski 1995; Brudzynski and Gibson 1997; Bardgett and Henry 1999). The VTA hypothesis suggests that NMDA receptor stimulation in the VH activates VTA dopaminergic neurons by means of a trans-synaptic activation (Legault and Wise 1999; Legault et al. 2000). In the present study evidence is presented for the existence of a local dopaminergic-receptor mediated inhibition of NMDA receptor activation in the $\mathrm{VH}$.

\section{MATERIALS AND METHODS}

\section{Animals}

A total of 54 adult male Sprague-Dawley rats (Sollentuna, Sweden), weighing 280-310 g at the time of testing, were used. At least a five-day adaptation period to the animal maintenance facilities of the department was allowed prior to any treatment. The rats were housed, in groups of four, in standard plastic Macrolon ${ }^{\circledR}$ IV cages $(57 \times 35 \times 19 \mathrm{~cm})$ up to the time of surgery. They were maintained at an ambient room temperature of $19 \pm$ $0.5^{\circ} \mathrm{C}$ with $40-50 \%$ relative humidity. A 12 -h light/dark schedule (lights on at 6 A.M.) was used throughout the experiment and the animals had lab chow and tap water ad libitum up to the time of each experiment. Following surgery the animals were housed in pairs in Akriform ${ }^{\circledR}$ cages $(48 \times 32 \times 16 \mathrm{~cm})$, with a transparent Plexiglas partition which allowed snout contact between the two animals. This procedure was used to avoid any possible influence of chronic stress on performance due to isolation. Animal housing and all experimental procedures followed the provisions and general recommendations of Swedish animal protection legislation.

\section{Stereotaxic Operations}

The rats were anesthetized with $60 \mathrm{mg} / \mathrm{kg}$ i.p. of sodium pentobarbital (Apoteksbolaget, Umea, Sweden). Body temperature during and after the surgery was maintained at $37^{\circ} \mathrm{C}$ using a thermostat-regulated heat pad (CMA/105, CMA/Microdialysis, Stockholm, Sweden). The anesthetized animal was placed in a stereotaxic frame (Kopf, Tujunga, CA, U.S.A.) with the incisor bar in the range of -2.7 to $-1.5 \mathrm{~mm}$ and permanent steel guide cannulae (26-gauge; $6.7 \mathrm{~mm}$ with a diameter of $0.45 \mathrm{~mm}$; Plastics One, Roanoke, VA, U.S.A.) were implanted into the $\mathrm{VH}$ bilaterally. The coordinates with respect to bregma were AP $-5.5 \mathrm{~mm}, \mathrm{~L} \pm 4.8 \mathrm{~mm}$ and $\mathrm{V}$ $-7.2 \mathrm{~mm}$ (injection site) (Paxinos and Watson (1986). The guide cannula was attached to the skull using two microscrews and acrylic dental cement and a dummy cannula was inserted into the entire length of each guide cannula to keep them patent during the recovery period. The animals were allowed to recover for one week before the start of the experiments.

\section{Microinfusions}

A microinfusion pump (CMA/100, CMA/Microdialysis, Stockholm, Sweden) was used to infuse all compounds (NMDA and/or the dopamine receptor antagonists) bilaterally and simultaneously into the $\mathrm{VH}(0.5$ $\mu \mathrm{l} /$ side) at a flow rate of $0.2 \mu \mathrm{l} / \mathrm{min}$. During the infusion the animals were held lightly by the experimenter, and the injection needles (Plastics One; 33 gauge; 0.5 $\mathrm{mm}$ longer than the guide cannula) were left for $1 \mathrm{~min}$ inside the guide cannulae after the infusion of the drugs to minimize backflow. After infusion the dummy cannulae were put back into the guide cannulae.

\section{Motor Activity Apparatus}

General motor activity, locomotion and rearing behavior were recorded by an M/P 40 Fc Electronic Motility Meter (Motron Products, Sweden) (Ögren et al. 1979). The apparatus consisted of a transparent perspex cage with the following dimensions: $24 \times 38 \times 30$ (height) $\mathrm{cm}$. The cage was situated below an infrared light and was located on an infrared photosensor array that provided quantitative recordings of horizontal movements of the rat by detecting infrared photocell interruptions. Horizontal movements were detected by 40 photosensors placed in the floor of the cage. The photosensors were mounted in $4 \times 4 \mathrm{~cm}$ squares covering the entire measurement area. General motor activity was defined as an interruption of a single photocell (movements of more than $4 \mathrm{~cm}$ ). Locomotion was de- 
fined as movement between the two rows of photosensors located at the short sides of the cage floor. The locomotor counts were, therefore, independent of the trajectory followed by the animal when travelling between these two opposite rows of photosensors (a distance of at least $32 \mathrm{~cm}$ ). Vertical movements (rearings) were recorded by a lateral infrared sensory array which registered photocell interruptions at $13 \mathrm{~cm}$ above the cage floor. The array consisted of five photocells located at 5-cm intervals across the short side of the cage. Rearing was defined as an interruption of a single lateral photocell. General motor activity, locomotion and rearing values were simultaneously recorded for 12 animals in different cages separated by opaque partitions.

\section{Behavioral Testing}

Animals were tested twice, in a crossed A-B, B-A design with one week in between. The two treatments were randomly determined for each animal. The first testing began on postoperative day 7 and all testing was performed between 8:00 A.M. and 3:00 P.M. All animals tested were brought to a room adjacent to the experimental room one hour prior to the start of the experiment. Then, the animals were placed individually in the activity cages for a habituation period of $60 \mathrm{~min}$. Thereupon, animals were consecutively taken to be injected intracerebrally (i.c.) with either NMDA $(0.05-1 \mu \mathrm{g} /$ side), the dopamine D2 receptor antagonist raclopride ( 1 or $5 \mu \mathrm{g} /$ side, equivalent to 2.0 and $10.0 \mu \mathrm{mol} /$ side, respectively), the dopamine $\mathrm{D} 1 / 5$ receptor antagonist SCH 23390 ( $1 \mu \mathrm{g} /$ side, equivalent to $3.1 \mu \mathrm{mol} /$ side $)$, artificial CSF or a solution of NMDA mixed with either raclopride or SCH 23390. The doses of NMDA and dopamine antagonists used are in the same range as those used in previous studies dealing with local VH administration (Yang and Mogenson 1987; Wu and Brudzynski 1995; Brudzynski and Gibson 1997; Bardgett and Henry 1999; Legault and Wise 1999; Wilkerson and Levin 1999). Immediately after the injection, the animals were placed back to their cages and motor activity was recorded for a period of $120 \mathrm{~min}$. After completion of the experiment, the location of the cannula tip was confirmed by histological examination of serial brain sections (Figure 1).

\section{Test Compounds}

The following compounds were used: NMDA (Sigma, St Louis, MO, U.S.A.), raclopride tartrate (Arcus Zeneca, Södertälje, Sweden), SCH $23390 \mathrm{HCl}$ (Sigma). The drugs were dissolved in artificial CSF $(123.4 \mathrm{mM} \mathrm{NaCl}, 23.4$ $\mathrm{mM} \mathrm{NaHCO}_{3}, 2.4 \mathrm{mM} \mathrm{KCl}, 0.5 \mathrm{mM} \mathrm{KH} \mathrm{PO}_{4}, 1.1 \mathrm{mM}$ $\mathrm{CaCl}_{2} .2 \mathrm{H}_{2} \mathrm{O}, 0.8 \mathrm{mM} \mathrm{MgCl}$. $6 \mathrm{H}_{2} \mathrm{O}, 0.5 \mathrm{mM} \mathrm{Na}_{2} \mathrm{SO}_{4}, 5.8$ $\mathrm{mM}$ glucose, $\mathrm{pH}$ 7.1). Artificial CSF and all solutions were prepared fresh for each experiment.

\section{Statistical Analysis}

In order to obtain homogeneity of variance all numerical values (number of counts $/ 10 \mathrm{~min}$ ) were transformed (square root of (counts +0.5$)$ ) (Melani et al. 1999) and analyzed by using the mean of all the transformed data during the first 1-h period after i.c. administration. The second 1-h period was not analyzed since NMDA did not induce significant motor activation dur-

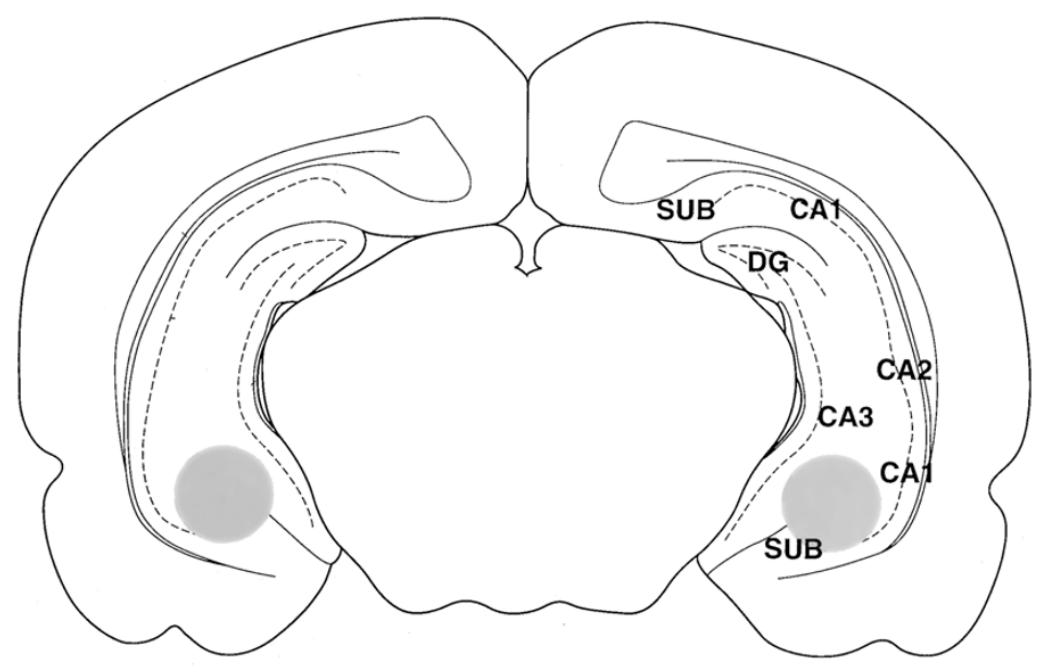

Figure 1. Scheme of the localization of the bilateral injection sites in the $\mathrm{VH}$ in a coronal brain section, which corresponds to AP -5.6 respect to bregma, from Paxinos and Watson (1986). The shaded areas correspond to the VH areas where all injection sites were found (no animals were discarded from the initial 54 rats). These injection sites were found mainly in the ventral CA1/CA3/subiculum. For simplicity, the boundaries of the injection sites in the AP plane are not shown. Those limits were from AP -4.8 to AP -6.04 . No damage other than that induced by the injection cannula was observed with any dose of NMDA. SUB: subiculum; DG: dentate gyrus. Scale bar: $1 \mathrm{~mm}$. 

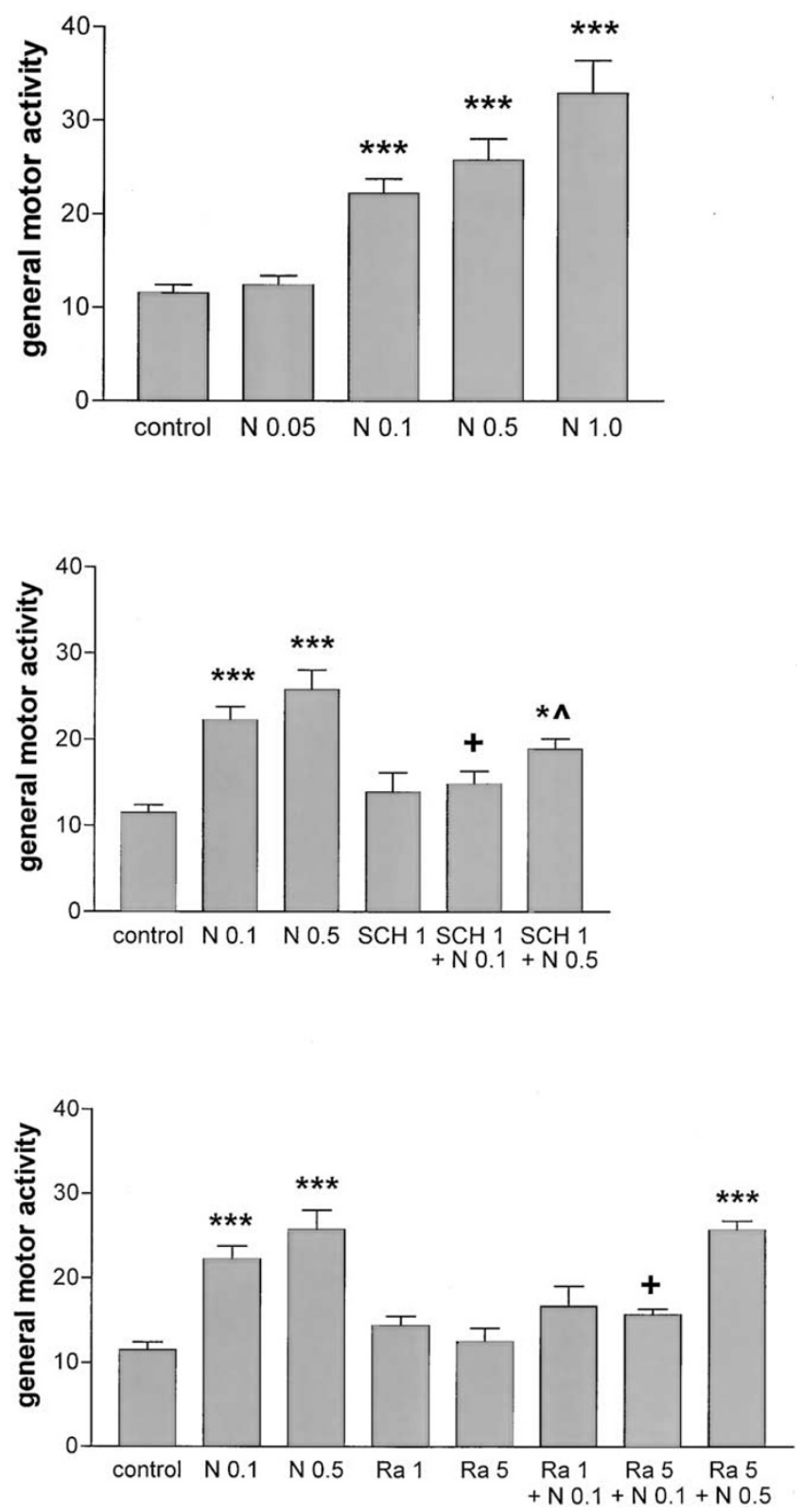

Figure 2. The results represent transformed data of general motor activity (means + S.E.M.) from $10 \mathrm{~min}$ sessions over 60 min of the observation period ( $n=6-12$ /group). Although the results of the control, $\mathrm{N} 0.1$ and $\mathrm{N} 0.5$ groups appear in the three graphs, all groups were statistically analyzed just once. $*, * * *$ significantly different as compared with vehicle control (artificial CSF alone) (ANOVA with post-hoc Newman-Keuls comparisons, $p<.05$ and $p<.001$, respectively); + significantly different compared with N 0.1 (ANOVA, $p<.05$ ); ${ }^{\wedge}$ significantly different compared with N 0.5 (ANOVA, $p<.05$ ). $\mathrm{N} 0.05, \mathrm{~N} 0.1, \mathrm{~N} 0.5$ and N 1.0: 0.05, 0.1, 0.5 and $1.0 \mu \mathrm{g}$ of NMDA/side, respectively. SCH 1: SCH $233901 \mu \mathrm{g} /$ side. Ra 1 and Ra 5: raclopride 1 and $5 \mu \mathrm{g} /$ side, respectively.

ing this period. Significant differences among all the 13 differently treated groups were simultaneously evaluated by 1-way analysis of variance (ANOVA) followed by Newman-Keuls multiple comparison tests. Al-
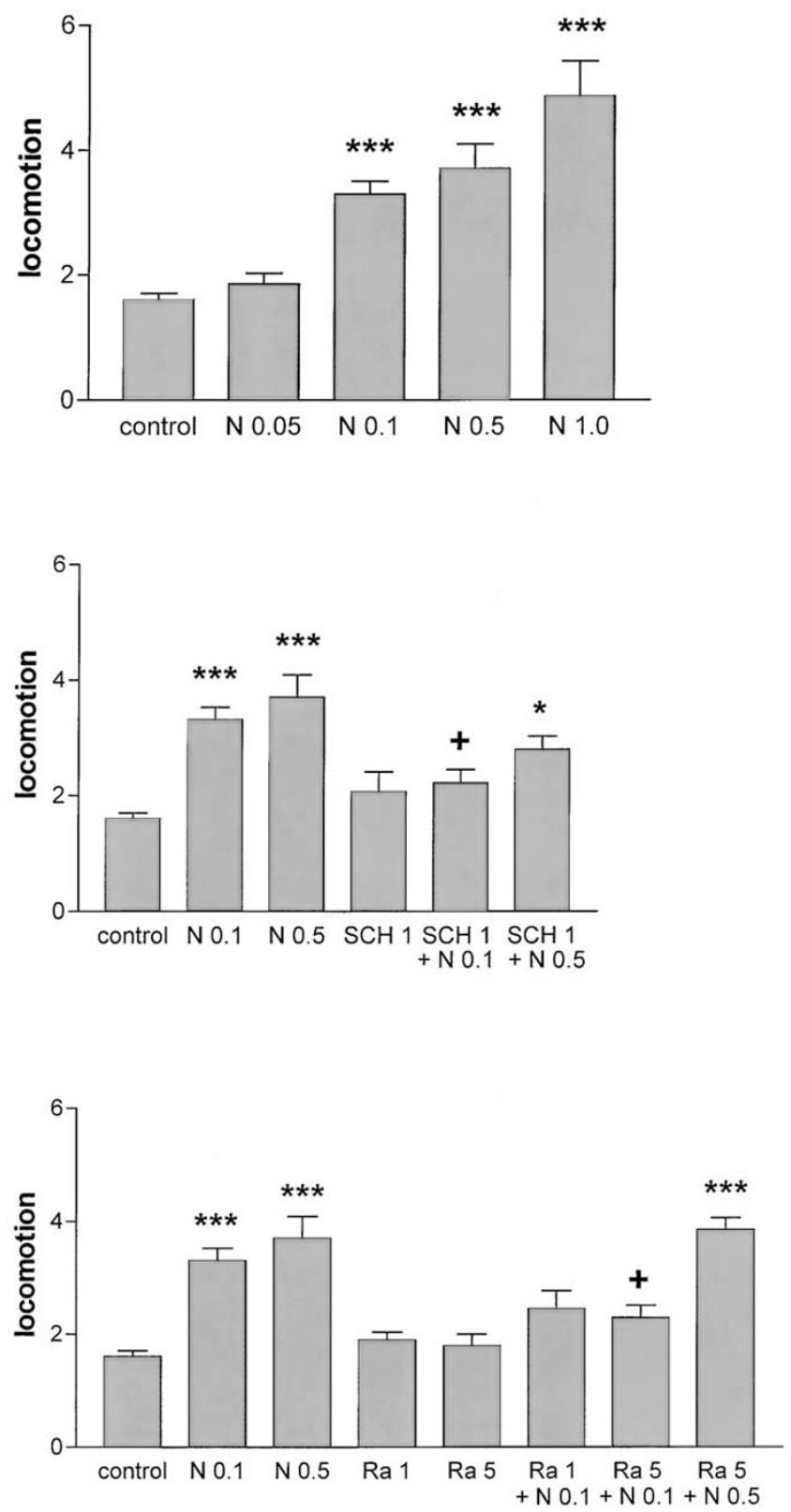

Figure 3. The results represent transformed data of locomotion (means + S.E.M.) from $10 \mathrm{~min}$ sessions over $60 \mathrm{~min}$ of the observation period ( $n=6-12$ /group). Although the results of the control, $\mathrm{N} 0.1$ and $\mathrm{N} 0.5$ groups appear in the three graphs, all groups were statistically analyzed just once. * ,*** significantly different as compared with vehicle control (artificial CSF alone) (ANOVA with post-hoc NewmanKeuls comparisons, $p<.05$ and $p<.001$, respectively); + significantly different compared with $\mathrm{N} 0.1$ (ANOVA, $p<$ .05). N 0.05, N 0.1, N 0.5 and N 1.0: 0.05, 0.1, 0.5 and $1.0 \mu \mathrm{g}$ of NMDA/side, respectively. SCH 1: SCH $233901 \mu \mathrm{g} /$ side. Ra 1 and Ra 5: raclopride 1 and $5 \mu \mathrm{g} /$ side, respectively.

though the results of the control group and the groups treated with $0.1 \mu \mathrm{g}$ and $0.5 \mu \mathrm{g}$ of NMDA are shown repeatedly in the figures, they were statistically analyzed only once. 

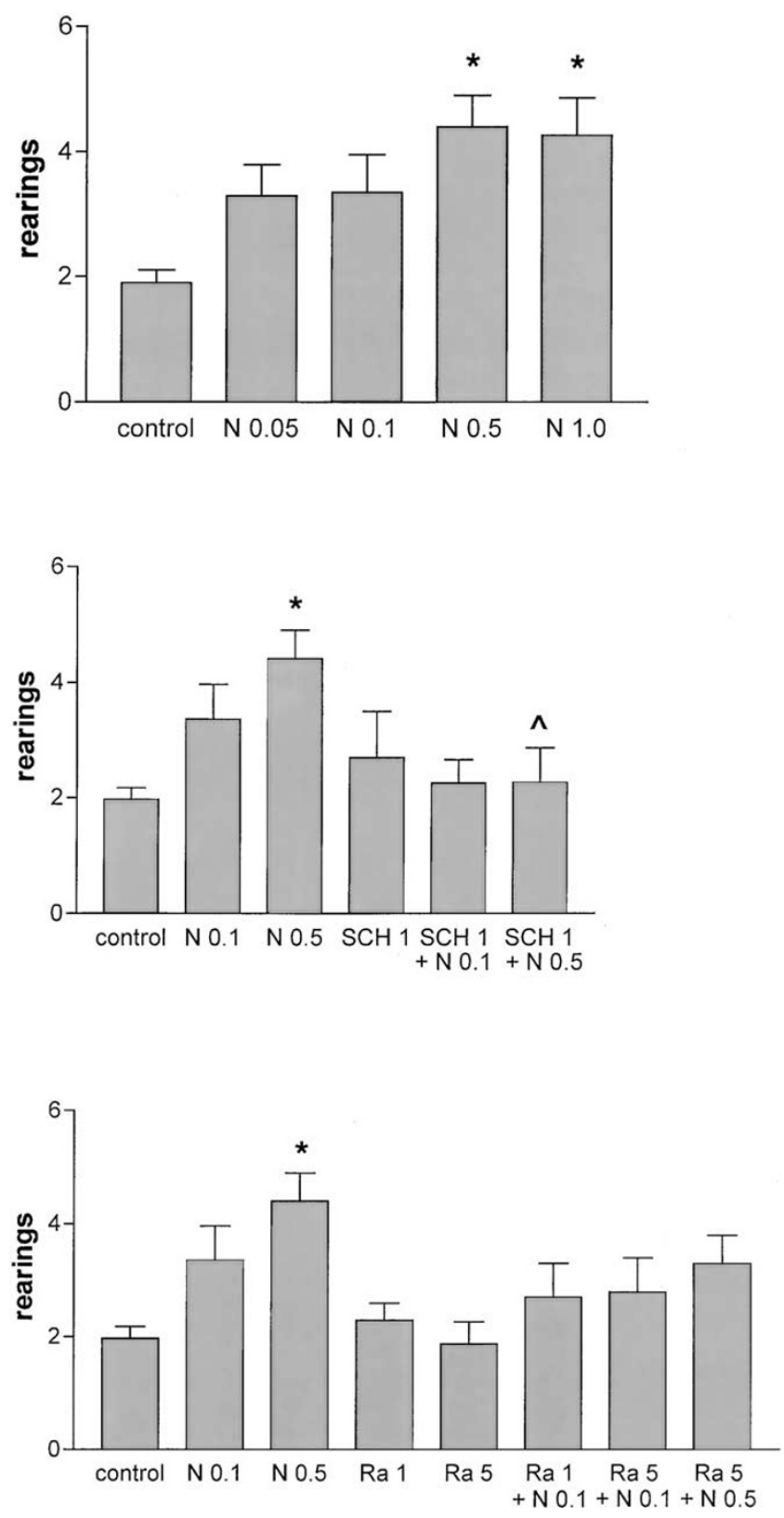

Figure 4. The results represent transformed data of rearings (means + S.E.M.) from $10 \mathrm{~min}$ sessions over $60 \mathrm{~min}$ of the observation period ( $n=6-12$ /group). Although the results of the control, N 0.1 and N 0.5 groups appear in the three graphs, all groups were statistically analyzed just once. * significantly different as compared with vehicle control (artificial CSF alone) (ANOVA with post-hoc Newman-Keuls comparisons, $p<.05$ ). $\mathrm{N} 0.05, \mathrm{~N} 0.1, \mathrm{~N} 0.5$ and N 1.0: 0.05, 0.1, 0.5 and $1.0 \mu \mathrm{g}$ of NMDA/side, respectively. SCH 1: SCH $233901 \mu \mathrm{g} /$ side. Ra 1 and $\mathrm{Ra}$ 5: raclopride 1 and $5 \mu \mathrm{g} /$ side, respectively.

\section{RESULTS}

\section{Effects of the VH Bilateral Injection of NMDA on the Motor Activity of Rats}

NMDA caused a dose-dependent increase of motor activity compared with the control group. The increase reached significance at the dose of $0.1 \mu \mathrm{g} /$ side both for general motor activity and locomotion (Figure 2 and Figure 3). Rearings were only significantly increased with the highest doses tested (0.5 and $1 \mu \mathrm{g} / \mathrm{side}$ ) (Figure 4). With these high doses of NMDA (0.5 and $1 \mu \mathrm{g} /$ side) the increase in motor activity was associated (in most of the cases) with wet-dog shakes and fast or explosive running. The animals did not show tonic-clonic convulsions or partial motor seizures.

\section{Effects of the VH Bilateral Injection of the Dopamine Receptor Antagonists Raclopride and SCH 23390 on the NMDA-induced Motor Activity}

Neither raclopride (1 or $5 \mu \mathrm{g} /$ side) nor SCH 23390 (1 $\mu \mathrm{g} /$ side) induced any significant change in motor activity compared with the control group, but both compounds significantly reversed the motor activation induced by NMDA (Figures 2, 3 and 4). Nevertheless, the dopamine $\mathrm{D}_{1}$ receptor antagonist $\mathrm{SCH} 23390$ was more potent than the dopamine $\mathrm{D}_{2}$ receptor antagonist raclopride. Thus, $1 \mu \mathrm{g}$ of SCH $23390(3 \mu \mathrm{mol} / \mathrm{side})$ prevented the increase in general motor activity induced by 0.1 and $0.5 \mu \mathrm{g}$, while $5 \mu \mathrm{g}$ of raclopride $(10 \mu \mathrm{mol} /$ side) could only counteract the effect of $0.1 \mu \mathrm{g}$ of NMDA (Figure 2). Similarly, $1 \mu \mathrm{g}$ of SCH 23390 and 5 $\mu \mathrm{g}$ of raclopride significantly antagonized the increase in locomotion induced by $0.1 \mu \mathrm{g}$ (but not $0.5 \mu \mathrm{g}$ ) of NMDA. Finally, The increase in rearings induced by 0.5 $\mu \mathrm{g}$ of NMDA could only be significantly antagonized by $1 \mu \mathrm{g}$ of SCH 23390, while raclopride was ineffective.

\section{DISCUSSION}

The present data confirm previous studies showing that the unilateral or bilateral infusion of NMDA in the $\mathrm{VH}$ produces motor activation in rodents (Yang and Mogenson 1987; Wu and Brudzynski 1995; Brudzynski and Gibson 1997; Bardgett and Henry 1999; Legault and Wise 1999). Bardgett and Henry (1999) have recently shown that activation of NMDA receptors in the $\mathrm{VH}$ has a much greater effect on motor activity relative to activation of other amino acid receptor subtypes (AMPA, kainic acid and metabotropic glutamate receptors). It has been proposed that this NMDA-mediated motor activation depends on dopaminergic neurotransmission (see the introductory paragraphs). The nucleus accumbens and the VTA have been suggested to be the main loci where dopamine is acting as a positive modulator of the VH NMDA receptor-mediated motor activating effects (Wu and Brudzynski 1995; Brudzynski and Gibson 1997; Legault and Wise 1999; Legault et al. 2000). Another possible locus of NMDA receptor-dopamine interaction is the VH itself. In fact, the hippocampus receives dopamine innervation, mostly from VTA, and contains 
dopamine receptors of both the D1/5 and D2 subtypes (Bischoff 1986; Verney et al. 1985; Köhler et al. 1991). Furthermore, the VH contains the highest density of hippocampal dopamine innervation (Verney et al. 1985).

Since coinfusion of dopamine antagonists could completely prevent the motor activity induced by the NMDA, these results demonstrate the existence of a strong tonic facilitating effect of dopamine on NMDA receptor-mediated effects in the $\mathrm{VH}$. The more potent effect of SCH 23390 versus raclopride suggests that dopamine receptors of the D1/5 subtype are particularly involved. On the other hand, Wilkerson and Levin (1999) have recently shown than VH infusion of raclopride, but not $\mathrm{SCH} 23390$, is effective at impairing spatial working memory. The potent hippocampal NMDA receptor-dopamine D1 receptor interaction shown in the present study can also explain recent experimental findings by other research groups. Thus, Radulovic et al. (2000) showed that the increase in the expression of $c$-fos in the hippocampus induced by the systemic administration of NMDA in mice is completely counteracted by the previous systemic administration of $\mathrm{SCH} 23390$, but not by the dopamine D2 antagonist sulpiride. Also, systemic SCH 23390, but not sulpiride, inhibited the motor activity induced by $\mathrm{VH}$ electrical stimulation (Taepavarapruk et al. 2000). At a more molecular level dopamine $\mathrm{D} 1 / \mathrm{D} 5$ receptor activation in the hippocampus has been shown to enhance NMDA receptor-mediated currents (Yang 2000). Also, there are experimental data supporting the existence of dopamine D1/D5 receptor-NMDA receptor interactions involving plastic changes in hippocampal excitatory synaptic transmission. Thus, D1/ D5 receptors appear to play an important role in the hippocampal "late phase" long-term potentiation (L-LTP) (Frey et al. 1993; Huang and Kandel 1995; Matthies et al. 1997). The present findings show that, in addition to the VTA and the nucleus accumbens (see introduction), the $\mathrm{VH}$ is an important locus of interaction between dopamine and glutamate in relation to the control of motor activity. Furthermore, these findings provide new aspects on dopamine-glutamate interactions in the limbic system, which might be of relevance for schizophrenia (Lipska and Weinberger 2000) and drug addiction (Berke and Hyman 2000).

\section{ACKNOWLEDGMENTS}

Work supported by the Karolinsla Institute Funding and a postdoctoral grant to L. Giménez-Llort (MEC, Spain).

\section{REFERENCES}

Bardgett ME, Henry JD (1999): Locomotor activity and accumbens fos expression driven by ventral hippocam- pal stimulation require D1 and D2 receptors. Neuroscience 94:59-70

Berke JD, Hyman SE (2000): Addiction, dopamine, and the molecular mechanisms of memory. Neuron 25:515-532

Bischoff S (1986): Mesohippocampal dopamine system. Characteristics, functional and clinical implications. In Isaacson RL, Pribram KH (eds), The Hippocampus, Vol. 3. New York, Plenum Press, pp 1-32

Brudzynski SM, Gibson CJ (1997): Release of dopamine in the nucleus accumbens caused by stimulation of the subiculum in freely moving rats. Brain Res Bull 42:303-308

Ferré S, Tusell JM, Barron S, Giménez-Llort L, Martínez E, Serratosa J (1996): Reserpine potentiates NMDAinduced c-fos mRNA expression in the mouse brain. Neurosci Lett 212:147-150

Frey U, Huang YY, Kandel ER (1993): Effects of cAMP simulate a late stage of LTP in hippocampal CA1 neurons. Science 260:1661-1664

Giménez-Llort L, Martínez E, Ferré S (1995): Dopamineindependent and adenosine-dependent mechanisms involved in the effects of N-methyl-D-aspartate on motor activity in mice. Eur J Pharmacol 275:171-177

Giménez-Llort L, Martínez E, Ferré S (1997): Different effects of dopamine antagonists on spontaneous and NMDAinduced motor activity in mice. Pharmacol Biochem Behav 56:549-553

Huang Y-Y, Kandel ER (1995): D1/D5 receptor agonists induce a protein synthesis-dependent late potentiation in the CA1 region of the hippocampus. Proc Natl Acad Sci USA 92:2446-2450

Klockgether T, Turski L (1993): Toward an understanding of the role of glutamate in experimental parkinsonism: Agonist-sensitive sites in the basal ganglia. Ann Neurol 34:585-593

Köhler C, Ericson H, Radesäter AC (1991): Different laminar distributions of dopamine D1 and D2 receptors in the rat hippocampal region. Neurosci Lett 126:107-109

Legault M, Wise RA (1999): Injections of N-methyl-D-aspartate into the ventral hippocampus increase extracellular dopamine in the ventral tegmental area and nucleus accumbens. Synapse 31:241-249

Legault M, Rompré P-P, Wise RA (2000): Chemical stimulation of the ventral hippocampus elevates nucleus accumbens dopamine by activating dopaminergic neurons of the ventral tegmental area. J Neurosci 20:1635-1642

Lipska BK, Weinberger DR (2000): To model a psychiatric disorder in animals: Schizophrenia as a reality test. Neuropsychopharmacology 23:223-239

Matthies H, Becker A, Schroeder H, Kraus J, Hollt V, Krug M (1997): Dopamine D1-deficeint mutant mice do not express the late phase of hippocampal long-term potentiation. Neuroreport 8:3533-3535

Melani A, Corsi C, Giménez-Llort, Martínez E, Ogren SO, Pedata F, Ferré S (1999): Effect of N-methyl-D-aspartate on motor activity and in vivo adenosine striatal outflow in the rat. Eur J Pharmacol 385:15-19

Ögren SO, Köhler C, Fuxe K, Ankeby K (1979): Behavioural effects of ergot drugs. In Fuxe K, Calne DB (eds), Dopamine Ergot Derivatives and Motor Function. Oxford, Pergamon Press, pp 187-205 
Paxinos G, Watson C (1986): The Rat Brain in Stereotaxic Coordinates. Sydney, Academic Press

Radulovic J, Blank T, Nijholt, Kammermeier J, Spiess J (2000): In vivo NMDA/dopamine interaction resulting in Fos production in the limbic system and basal ganglia of the mouse brain. Mol Brain Res 75:271-280

Taepavarapruk P, Floresco SB, Phillips AG (2000): Hyperlocomotion and increased dopamine efflux in the rat nucleus accumbens evoked by electrical stimulation of the ventral subiculum: role of ionotropic glutamate and dopamine D1 receptors. Psychopharmacology (Berl) 151:242-251

Verney C, Baulac M, Berger B, Alvarez C, Vigny A, Helle KB (1985): Morphological evidence for a dopaminergic terminal field in the hippocampal formation of young and adult rat. Neuroscience 14:1039-1052
Wilkerson A, Levin ED (1999): Ventral hippocampal dopamine D1 and D2 systems and spatial working memory in rats. Neuroscience 89:743-749

Wu M, Brudzynski SM (1995): Mesolimbic dopamine terminals and locomotor activity induced from the subiculum. Neuroreport 6:1601-1604

Yang S-N, Mogenson GJ (1987): Hippocampal signal transmission to the pedunculopontine nucleus and its regulation by dopamine D2 receptors in the nucleus accumbens: An electrophysiological and behavioral study. Neuroscience 23:1041-1055

Yang S-N (2000): Sustained enhancement of AMPA receptor- and NMDA receptor-mediated currents induced by dopamine D1/D5 receptor activation in the hippocampus: An essential role of postsynaptic $\mathrm{Ca}^{2}+$. Hippocampus 10:57-63 